\title{
Biological carbon sequestration and carbon trading re-visited
}

\author{
G. Cornelis van Kooten
}

Received: 9 December 2007 / Accepted: 9 December 2008 / Published online: 23 April 2009

(C) The Author(s) 2009. This article is published with open access at Springerlink.com

\begin{abstract}
Biological activities that sequester carbon create $\mathrm{CO}_{2}$ offset credits that could obviate the need for reductions in fossil fuel use. Credits are earned by storing carbon in terrestrial ecosystems and wood products, although $\mathrm{CO}_{2}$ emissions are also mitigated by delaying deforestation, which accounts for one-quarter of anthropogenic $\mathrm{CO}_{2}$ emissions. However, non-permanent carbon offsets from biological activities are difficult to compare with each other and with emissions reduction because they differ in how long they prevent $\mathrm{CO}_{2}$ from entering the atmosphere. This is the duration problem. It results in uncertainty and makes it hard to determine the legitimacy of biological activities in mitigating climate change. Measuring, verifying and monitoring the carbon sequestered in sinks greatly increases transaction costs and leads to rent seeking by sellers of dubious sink credits. While biological sink activities undoubtedly help mitigate climate change and should not be neglected, it is shown that there are limits to the substitutability between temporary offset credits from these activities and emissions reduction, and that this has implications for carbon trading. A possible solution to inherent incommensurability between temporary and permanent credits is also suggested.
\end{abstract}

\section{Introduction}

Policy makers at all levels are seriously considering the potential role of terrestrial ecosystems and geological reservoirs for storing carbon, thereby creating $\mathrm{CO}_{2}$ offsets that could obviate the need for lifestyle-changing reductions in fossil fuel use. Some scientists claim that, by converting marginal croplands to permanent grasslands or

G. Cornelis van Kooten $(\bowtie)$

Department of Economics, University of Victoria, P.O. Box 1700,

Stn CSC, Victoria, BC V8W 2Y2, Canada

e-mail: kooten@uvic.ca 
forests, the accompanying increase in biomass and soil organic carbon can offset $20 \%$ or more of global fossil fuel emissions (Sathaye et al. 2001; Lal 2004a, b). The Government of Canada (2002) had planned to rely on tree planting and improved forest management for meeting some one-third of its Kyoto commitment, but subsequent losses of large swaths of timber to Mountain Pine Beetle and wildfire greatly reduced the expected role of forests. Proponents of $\mathrm{CO}_{2}$ capture and storage in deep underground aquifers and abandoned oil/gas fields indicate that there is enough available storage to trap decades of $\mathrm{CO}_{2}$ emissions (Parson and Keith 1998). The costs of this option are unknown as there is a risk of sudden future release of deadly concentrations of $\mathrm{CO}_{2}-\mathrm{a}$ cost to be evaluated by the willingness of people to pay to avoid such a risk and not unlike that associated with long-term storage of nuclear waste, which could be substantial (see Riddel and Shaw 2003).

There is no lack of schemes to generate carbon credits through terrestrial activities. Even a cursory investigation finds there are many 'sellers' of carbon offset credits. Examples include:

- Greenfleet (http://www.greenfleet.com.au/greenfleet/objectives.asp, viewed 17 Sep 2008). "For $\$ 51$ (tax deductible), Greenfleet will plant 17 native trees [that]... will help to create a forest, and as they grow will absorb the greenhouse gases generated by driving your car for one year". This project is designed to increase planting of native species in Australia, with the sale of $\mathrm{CO}_{2}$ off set credits helping to pay for tree planting. Although there is insufficient information about the timing of carbon uptake and release to determine the true cost, data provided by Greenfleet suggest that costs are about US $\$ 12.82 / \mathrm{tCO}_{2}$.

- Trees for Life (http://www.treesforlife.org.uk/tfl.global_warming.html, viewed 17 Sep 2008). This conservation charity is dedicated to the regeneration and restoration of the Caledonian Forest in the Highlands of Scotland. It invites individuals and organizations to become 'carbon conscious' and uses the idea of a carbon footprint to solicit donations from individuals of $£ 60(\$ 120), £ 140(\$ 280)$ and $£ 280$ (\$360) depending on whether one’s 'carbon footprint' is rated as light, medium or heavy (a guide is provided). Organizations are asked to contribute much more. For each $£ 5(\$ 10)$ donation, Trees for Life claims to plant one tree. No other details are available.

- Haida-Gwaii Climate Forest Pilot Project (http://www.haidaclimate.com/, viewed 17 Sep 2008). The Haida-Gwaii First Nation on the Queen Charlotte Islands off the northern coast of British Columbia intends to restore some 5,000 to 10,000 ha of degraded riparian habitat. It hopes to fund the entire project by selling carbon credits, although alder that is "growing in an un-natural manner" would first need to be removed. The preferred mixed-conifer climax rainforest will eventually sequester $1928-2454 \mathrm{tCO}_{2} /$ ha. Little in the way of cost data is provided and there is no indication about the timing of carbon uptake or potential future release, or loss of carbon from removing alder.

Given that the Haida Gwaii are committed to restoring ancient forests because they are part of their cultural heritage, and that Trees for Life is committed to restoring the Caledonian Forest, the sale of carbon credits is part of a marketing technique to solicit funds for a project that may or may not have proceeded in any event.

Some of the now many biological sink projects available to would-be purchasers of emission offsets provide clear carbon uptake benefits but others are more dubious 
in nature. In some cases, projects are promoted because it happens to be convenient at the time. For example, a native group in northern Alberta sought tradable carbon permits for delaying timber harvests, a delay caused by low prices associated with a decline in lumber demand; the request was subsequently turned down by the Canadian government. ${ }^{1}$ In other cases, such as that of a community group in Powell River, British Columbia, sale of carbon credits is necessary to help fund activities to prevent the harvest of coastal rainforest. The latter constitutes a forest conservation activity that generates real carbon-uptake services, although one might want to consider whether the site could not generate even more carbon-uptake services if it were harvested and replanted (as required by law). Likewise, tree planting projects that would proceed at a slower pace without carbon payments, such as those mentioned above, might well generate legitimate carbon off set credits.

Unfortunately, not only is it difficult to determine whether a carbon sequestration project is additional, but many other aspects of a carbon sequestration project are unknown and perhaps unknowable. Even when projects are declared legitimate by a certifying authority, information about the amount and timing of carbon uptake, release due to harvests or unexpected denudation by wildfire, pests or disease, and other aspects of the project is often lacking. For many CDM-initiated forestry activities that seek to create carbon credits, for example, projects fail to identify all of the carbon sequestration costs, the future path of carbon uptake and harvests, the risks of forest denudation, and so forth. Yet, many such projects are simply funded by international agencies, or 'picked up' by companies seeking to improve their corporate image.

In a review of terrestrial carbon sequestration, the FAO (2004) examined 49 projects that were underway or proposed to create offset credits. Forty-three were in developing countries and eligible for CDM credits-38 were forestry projects, of which 17 involved forest conservation. While all projects had local or offshore sponsors and/or investors (a country and/or company), only 33 of the 49 projects managed to provide some information on the amount of carbon to be sequestered. Data on the amount of carbon sequestered could be considered 'good' for only 24 projects, although none provided an indication of the timing of carbon benefits. Information on costs was provided for only 11 projects.

Unlike emissions reduction, biological sink activities are not transparent regarding $\mathrm{CO}_{2}$ flux. To determine how much $\mathrm{CO}_{2}$ biological sink projects actually remove from the atmosphere, which is likely necessary to facilitate seamless trading between carbon sink and emissions reduction offset credits, requires high transaction costs related to measurement, monitoring and accounting of $\mathrm{CO}_{2}$ flux. Given that these high transaction costs militate against sinks, there is potential for rent seeking via dubious carbon sink projects.

The main argument for including biological sink activities in a strategy for mitigating climate change is that they enable society to lower atmospheric $\mathrm{CO}_{2}$ now while buying time to develop and implement new technologies for reducing future $\mathrm{CO}_{2}$ emissions. Thus, the economic benefit of biological carbon sinks relates as much to their value as a 'bridge' to the future as it does to their value in reducing atmospheric

\footnotetext{
${ }^{1}$ The groups mentioned here approached the author for advice on obtaining carbon credits.
} 
$\mathrm{CO}_{2}$. In that case, the future release of stored carbon (say, in 30 years) and the timing of carbon uptake are less of a concern. The objective in this paper is to examine this issue more closely, to consider whether sinks fulfill this role.

The problem is that emissions reduction and carbon sequestration, while opposite sides of the same coin in some sense, are not directly comparable, thereby inhibiting their trade in carbon markets. The difficulty centers on the length of time that mitigation strategies withhold $\mathrm{CO}_{2}$ from entering the atmosphere-the duration problem. In this regard, carbon offset credits from agricultural activities are particularly ephemeral, while $\mathrm{CO}_{2}$ capture and storage might almost be considered permanent; forestry activities, on the other hand, lead to carbon sinks that have a more intermediary duration. The IPCC (2000) recognizes that the carbon embodied in forests, and especially agricultural ecosystems (grass and soils), is always at risk of accidental or deliberate release, but that avoided emissions are permanent, despite the fact that 'saved' fossil fuels might release stored $\mathrm{CO}_{2}$ at some future date (Herzog et al. 2003). ${ }^{2}$

In the remainder of this paper we investigate the role of duration in greater detail. This is done by expanding in comprehensive fashion on earlier work by Marland et al. (2001), Sedjo and Marland (2003), and Herzog et al. (2003). In particular, we compare carbon mitigation activities according to how long they are able to lower $\mathrm{CO}_{2}$ levels in the atmosphere. This is important because storage times differ even among terrestrial activities, with some being more permanent than others. In the formal analysis, we assume that every temporary credit must be demonstrably additional and explicitly measured, verified, monitored, recorded and tracked if it is to be directly comparable with a permanent one. This assumption is relaxed in the discussion, where we consider how and under what conditions temporary sinks might yet be used as a bridge to the future given they cannot substitute in straightforward manner for emissions reduction in carbon trading.

In the next section, we review the role of terrestrial carbon sinks for mitigating climate change. We then investigate the implications of non-permanence of biological sinks in a formal fashion to determine whether the stop-gap nature of forestry activities makes it difficult for producers and buyers of temporary carbon offsets to value them, thereby adding to transaction costs and inhibiting trades. This is not the same as asking whether forestry activities can make a reasonable and useful contribution to a country's overall mitigation strategy, although it does shed light on this issue. The formal analysis is followed by a discussion of its policy implications and a possible approach to resolving the problem of duration. The conclusions follow.

\section{Duration: non-permanence of greenhouse gas mitigation}

Land use, land-use change and forestry (LULUCF) activities remove carbon from the atmosphere and store it in biomass, and, under Kyoto, are eligible activities for creating carbon offset credits. Tree planting and activities that enhance tree

\footnotetext{
${ }^{2}$ As one reviewer pointed out, reducing fossil fuel emissions in countries that are party to the Kyoto Protocol, for example, will result more intensive use of fossil fuels in non-participating countries. This is a problem of leakage that, while important, is not the same as that of duration.
} 
growth are among the most important, although tree plantations release a substantial amount of their stored carbon once harvested, which could happen as soon as five years after establishment for some fast-growing species. Sequestered carbon might also be released as a result of wildfire, disease or pests (e.g., mountain pine beetle infestation in British Columbia).

Based on a meta-regression analysis of 68 studies, van Kooten and Sohngen (2007) estimated the potential marginal costs of creating carbon offset credits via different forestry activities. These are provided in Table 1. In many of the studies included in the analysis, and particularly for a large number of studies not included in the analysis because of lack of information, the actual number of offset credits (as opposed to total carbon) that could be counted as part of the project was not available. Less than $10 \%$ of studies provided information on the length of time that carbon was retained in sinks, although they did provide information on costs per unit of carbon sequestered. None explicitly included transaction costs.

Given that utility companies are banking on carbon credits costing no more than $\$ 20$ per metric ton of $\mathrm{CO}_{2}$ (see The Economist 2007), many forest activities would not be competitive with emissions reduction, according to Table 1 , because the opportunity cost of land is generally too high. This holds even when account is taken of carbon stored in wood products. Not surprisingly, because of lower land costs, tree planting in the tropics and some activities in the boreal region might be worth undertaking, as well as some in the US where rates of tree growth are exceptionally high. The only other exception occurs when trees are harvested and burned in place of fossil fuels to generate electricity, and then not in all locations. Of course, if transaction costs were included, the estimated costs could be doubled (Slangen et al. 2008, pp. 200-205).

Agricultural activities that enhance soil organic carbon and store carbon in biomass are also considered a means to create offset credits. Agricultural activities identified by the IPCC (2000) include re-vegetation (establishment of vegetation that does not meet the definitions of afforestation and reforestation), cropland management (greater use of conservation tillage, more set asides) and grazing management (manipulation of the amount and type of vegetation and livestock produced). These activities provide temporary off sets only. For example, one study found that all of the soil organic carbon stored as a result of 20 years of conservation tillage was released in a single year of conventional tillage (Stockfisch et al. 1999; also Olson et al. 2005).

During the 1990s, farmers increasingly adopted conservation tillage practices, particularly zero tillage cropping. Farmers who adopt zero tillage balance costs (lower yields, higher chemical outlays) against benefits (labor and machinery savings

Table 1 Marginal costs of creating carbon offset credits through forestry activities, various forestry activities and regions, $\$ / \mathrm{tCO}_{2}$

\begin{tabular}{llllr}
\hline Activity & Region & & & \\
\cline { 2 - 5 } & Global & Europe & Boreal & Tropics \\
\hline Planting & $\$ 22-33$ & $\$ 158-185$ & $\$ 5-128$ & $\$ 0-7$ \\
Planting \& fuel substitution & $\$ 0-49$ & $\$ 115-187$ & $\$ 1-90$ & $\$ 0-23$ \\
Forest management & $\$ 60-118$ & $\$ 198-274$ & $\$ 46-210$ & $\$ 34-63$ \\
Forest management \& fuel substitution & $\$ 48-77$ & $\$ 203-219$ & $\$ 44-108$ & $\$ 0-50$ \\
Forest conservation & $\$ 47-195$ & n.a. & n.a. & $\$ 26-136$ \\
\hline
\end{tabular}

Adapted from van Kooten and Sohngen (2007) 
Table 2 Cost of creating carbon credits via zero tillage agriculture, $\$$ per metric ton of $\mathrm{CO}_{2}$

\begin{tabular}{lcr}
\hline Region & Wheat & Other crops \\
\hline US South & $\$ 3$ to $\$ 4$ & $\$ 0.50$ to $\$ 1$ \\
Prairies & $\$ 105$ to $>\$ 500$ & $\$ 41$ to $\$ 57$ \\
US corn belt & $\$ 39$ to $\$ 51$ & $\$ 23$ to $\$ 24$ \\
\hline
\end{tabular}

Adapted from Manley et al. (2005)

due to reduced field operations, and carbon payments if any). Low output and chemical input prices during the 1990s meant that the gain to no-till offsets the financial loss due to lower yields and greater use of chemicals to control weeds. As prices and technologies change (e.g., due to incentives promoting biofuels), soil conservation practices could be reversed, thereby releasing carbon stored in soils.

It is also not uniformly true that zero tillage sequesters more carbon than conventional tillage (Baker et al. 2007; Manley et al. 2005), which would lead to extremely (even infinitely) high costs of creating carbon credits. Some cost estimates based on meta-analyses of 52 studies of soil carbon flux and 51 studies of cost differences between conventional and zero tillage are provided in Table 2. ${ }^{3}$ The estimates omit the increased emissions related to greater chemical use and, importantly, the transaction costs associated with measurement and monitoring. With the exception, perhaps, of the US South, the cost of generating carbon credits by changing agronomic practices is not competitive with emissions reduction if the latter cost $\$ 20 / \mathrm{tCO}_{2}$.

While biological carbon sequestration offers a bridge to the future, the ultimate focus of efforts to mitigate climate change is on the avoidance of greenhouse gas emissions associated with the burning of fossil fuels. What are the long-term consequences of reducing current fossil fuel use? Some argue that, by leaving fossil fuels in the ground, their eventual use is only delayed and, as with carbon sequestered in a biological sink, results in the same obligation for the future (Herzog et al. 2003). The reasoning behind this is that the price path of fossil fuels will be lower in the future because, by reducing use today, more fossil fuels are available in the future. However, if society commits to de-carbonizing the economy, behaviour changes and technology evolves in ways that reduce future demand for fossil fuels, much as wood used by locomotives was replaced by coal and then by diesel. Carbon in terrestrial sinks, on the other hand, always has the potential to be released.

In the literature, several proposals exist for addressing the ephemeral nature of biological sinks, both for purposes of carbon trading and policy evaluation (costbenefit analysis). Partial instead of full credits can be provided for storing carbon based on the perceived risk that carbon will be released from a sink at some future date. The buyer or seller may be required to take out an insurance policy, where the insurer will compensate for the losses associated with unexpected carbon release

\footnotetext{
${ }^{3}$ We focus on zero tillage because reduced tillage does not lower atmospheric $\mathrm{CO}_{2}$ as the carbon stored in soils is offset by that released by increased production, transportation and application of chemicals (West and Marland 2002).
} 
(Subak 2003). Alternatively, the buyer or seller can assure that the temporary activity will be followed by one that results in permanent emission reductions.

The ton-years approach specifies that emissions can be compensated for by removing $\mathrm{CO}_{2}$ from the atmosphere and storing it for a period before releasing it back to the atmosphere. The conversion rate between ton-years of (temporary) carbon sequestration and permanent tons of emissions reduction is specified in advance (Dutschke 2002; IPCC 2000). The conversion rate ranges from 42 to 150 ton-years of temporary storage to cover one permanent ton (and is based on forest rotation ages). Rather than the authority establishing a conversion factor, market forces might be relied on to determine the conversion rate between (permanent) emissions reduction and temporary removals of $\mathrm{CO}_{2}$ from the atmosphere (Marland et al. 2001; Sedjo and Marland 2003). However, temporary credits are likely to be discounted quite highly because of greater uncertainty (due to the risk of unanticipated release of stored carbon), higher transaction costs (related to measurement and monitoring), and seller-host liability for the sink at the end of the contract period (reducing supply of sink-related carbon uptake services).

The instrument adopted by the UNFCC for forestry projects under the CDM is the temporary certified emission reduction unit, denoted tCER. A tCER is purchased for a set period of time and, upon expiry, has to be covered by substitute credits or reissued credits if the original project is continued. However, because monitoring and verification (measurement) are onerous and international bookkeeping is required to keep track of credits, transaction costs are high and rent seeking through dubious projects is likely unavoidable.

\section{Comparing carbon credit values when duration differs across projects}

Consider a comparison between two climate change mitigation options, neither of which results in permanent removal of $\mathrm{CO}_{2}$ from the atmosphere. Suppose that the more permanent of the two, say a policy that leads to a lower current rate of $\mathrm{CO}_{2}$ emissions, leads to an increase in $\mathrm{CO}_{2}$ emissions $N$ years from now, as argued by Herzog et al. (2003); the more ephemeral project generates temporary offset credits through sequestration of $\mathrm{CO}_{2}$ in a forest ecosystem, but releases the $\mathrm{CO}_{2}$ in $n$ years. (The comparison could just as well be between two carbon sequestration projects of different durations.) What then is the value of a forest-sink offset credit relative to an emissions reduction credit? Suppose that a unit of $\mathrm{CO}_{2}$ not in the atmosphere is currently worth $\$ q$, but that the shadow price rises at an annual rate $\gamma<r$, where $r$ is the discount rate. Then the value of emissions reduction is:

$$
P=\sum_{t=1}^{N} \frac{(1+\gamma)^{t} q}{(1+r)^{t}}=\frac{1+\gamma}{r-\gamma} q\left[1-\left(\frac{1+\gamma}{1+r}\right)^{N}\right],
$$

while a sink offset would be worth some proportion $\alpha$ of the emissions reduction, or:

$$
\alpha P=\sum_{t=1}^{n} \frac{(1+\gamma)^{t} q}{(1+r)^{t}}=\frac{1+\gamma}{r-\gamma} q\left[1-\left(\frac{1+\gamma}{1+r}\right)^{n}\right] \text {. }
$$


Upon taking the ratio of Eq. 2 to Eq. 1 and simplifying, we obtain the value of 'temporary' relative to 'permanent' storage:

$$
\alpha=\frac{1-\left(\frac{1+\gamma}{1+r}\right)^{n}}{1-\left(\frac{1+\gamma}{1+r}\right)^{N}},
$$

which depends on the discount rate $(r)$, the time it takes a ton of $\mathrm{CO}_{2}$ stored in a forest ecosystem to return to the atmosphere $(n)$, and the time it takes a ton of $\mathrm{CO}_{2}$ not emitted today to increase emissions at a future date $(N)$. Notice that the value does not depend on the price of carbon $(q)$. As indicated in Table 3, the proportional value of a sink credit to an emissions reduction credit $(\alpha)$ varies depending on the

Table 3 Value of a temporary relative to a permanent carbon credit $(\alpha)$, various scenarios

\begin{tabular}{|c|c|c|c|c|c|c|c|c|c|}
\hline \multirow[t]{2}{*}{$n$ to $N$ ratio } & \multicolumn{3}{|c|}{$N=100$ years discount rate } & \multicolumn{3}{|c|}{$N=200$ years discount rate } & \multicolumn{3}{|c|}{$N=500$ years discount rate } \\
\hline & $2 \%$ & $5 \%$ & $10 \%$ & $2 \%$ & $5 \%$ & $10 \%$ & $2 \%$ & $5 \%$ & $10 \%$ \\
\hline \multicolumn{10}{|c|}{ Growth rate of shadow price of carbon, $\gamma=0$} \\
\hline 0.01 & 0.023 & 0.048 & 0.091 & 0.040 & 0.093 & 0.174 & 0.094 & 0.216 & 0.379 \\
\hline 0.05 & 0.109 & 0.218 & 0.379 & 0.183 & 0.386 & 0.614 & 0.390 & 0.705 & 0.908 \\
\hline 0.10 & 0.208 & 0.389 & 0.615 & 0.333 & 0.623 & 0.851 & 0.629 & 0.913 & 0.991 \\
\hline 0.15 & 0.298 & 0.523 & 0.761 & 0.457 & 0.769 & 0.943 & 0.774 & 0.974 & 0.999 \\
\hline 0.20 & 0.379 & 0.628 & 0.851 & 0.558 & 0.858 & 0.978 & 0.862 & 0.992 & 1.000 \\
\hline 0.25 & 0.453 & 0.710 & 0.908 & 0.641 & 0.913 & 0.991 & 0.916 & 0.998 & 1.000 \\
\hline 0.30 & 0.520 & 0.775 & 0.943 & 0.709 & 0.947 & 0.997 & 0.949 & 0.999 & 1.000 \\
\hline \multicolumn{10}{|c|}{ Growth rate of shadow price of carbon, $\gamma=0.01$} \\
\hline 0.01 & 0.016 & 0.039 & 0.082 & 0.023 & 0.075 & 0.157 & 0.048 & 0.177 & 0.347 \\
\hline 0.05 & 0.077 & 0.180 & 0.347 & 0.109 & 0.322 & 0.574 & 0.220 & 0.621 & 0.882 \\
\hline 0.10 & 0.150 & 0.329 & 0.574 & 0.208 & 0.540 & 0.819 & 0.392 & 0.857 & 0.986 \\
\hline 0.15 & 0.219 & 0.451 & 0.722 & 0.297 & 0.688 & 0.923 & 0.526 & 0.946 & 0.998 \\
\hline 0.20 & 0.285 & 0.551 & 0.819 & 0.378 & 0.789 & 0.967 & 0.631 & 0.979 & 1.000 \\
\hline 0.25 & 0.348 & 0.634 & 0.882 & 0.452 & 0.857 & 0.986 & 0.713 & 0.992 & 1.000 \\
\hline 0.30 & 0.408 & 0.703 & 0.923 & 0.519 & 0.903 & 0.994 & 0.778 & 0.997 & 1.000 \\
\hline \multicolumn{10}{|c|}{ Growth rate of shadow price of carbon, $\gamma=0.02$} \\
\hline 0.01 & n.a. & 0.030 & 0.073 & n.a. & 0.056 & 0.140 & n.a. & 0.135 & 0.314 \\
\hline 0.05 & n.a. & 0.143 & 0.315 & n.a. & 0.252 & 0.530 & n.a. & 0.516 & 0.849 \\
\hline 0.10 & n.a. & 0.266 & 0.530 & n.a. & 0.441 & 0.779 & n.a. & 0.765 & 0.977 \\
\hline 0.15 & n.a. & 0.373 & 0.678 & n.a. & 0.583 & 0.896 & n.a. & 0.886 & 0.997 \\
\hline 0.20 & n.a. & 0.466 & 0.780 & n.a. & 0.688 & 0.951 & n.a. & 0.945 & 0.999 \\
\hline 0.25 & n.a. & 0.546 & 0.849 & n.a. & 0.768 & 0.977 & n.a. & 0.973 & 1.000 \\
\hline 0.30 & n.a. & 0.615 & 0.897 & n.a. & 0.827 & 0.989 & n.a. & 0.987 & 1.000 \\
\hline \multicolumn{10}{|c|}{ Growth rate of shadow price of carbon, $\gamma=0.04$} \\
\hline 0.01 & n.a. & 0.015 & 0.055 & n.a. & 0.022 & 0.106 & n.a. & 0.047 & 0.245 \\
\hline 0.05 & n.a. & 0.076 & 0.245 & n.a. & 0.107 & 0.429 & n.a. & 0.215 & 0.754 \\
\hline 0.10 & n.a. & 0.148 & 0.431 & n.a. & 0.204 & 0.674 & n.a. & 0.383 & 0.939 \\
\hline 0.15 & n.a. & 0.217 & 0.571 & n.a. & 0.293 & 0.814 & n.a. & 0.516 & 0.985 \\
\hline 0.20 & n.a. & 0.283 & 0.677 & n.a. & 0.373 & 0.894 & n.a. & 0.621 & 0.996 \\
\hline 0.25 & n.a. & 0.345 & 0.757 & n.a. & 0.446 & 0.939 & n.a. & 0.704 & 0.999 \\
\hline 0.30 & n.a. & 0.405 & 0.817 & n.a. & 0.512 & 0.965 & n.a. & 0.768 & 1.000 \\
\hline
\end{tabular}

n.a. not applicable as calculation cannot be made 
relationship between $n$ and $N$, the discount rate, and the growth rate $(\gamma)$ in damages from atmospheric concentrations of $\mathrm{CO}_{2}$. It is possible to prove some general results.

Proposition 1 For fixed and finite $N>0$, as $n / N \rightarrow 0$, the value of temporary storage relative to permanent emissions reduction goes to zero. The more ephemeral a sink project, the less valuable it is relative to emissions reduction.

Proof This proposition is obvious. Nonetheless, differentiate Eq. 3 with respect to $n$ and $N$, and sign the results.

$$
\begin{gathered}
\frac{\partial \alpha}{\partial n}=-\frac{\left(\frac{1+\gamma}{1+r}\right)^{n} \ln \left(\frac{1+\gamma}{1+r}\right)}{1-\left(\frac{1+\gamma}{1+r}\right)}>0 . \\
\frac{\partial \alpha}{\partial N}=\frac{\left[1-\left(\frac{1+\gamma}{1+r}\right)^{n}\right]\left(\frac{1+\gamma}{1+r}\right)^{N} \ln \left(\frac{1+\gamma}{1+r}\right)}{\left[1-\left(\frac{1+\gamma}{1+r}\right)^{N}\right]^{2}}<0 .
\end{gathered}
$$

The reason for the signs is that the natural logarithm of a number less than 1 is negative (recall $\gamma<r$ ). Clearly, as the length of temporary storage decreases relative to the 'permanent' $\mathrm{CO}_{2}$ emission reduction, result (Eq. 4) indicates that the value of a temporary sink relative to an emission reduction falls (because all other things are held constant - the ceteris paribus condition); thus, for a given $N$, as $n / N \rightarrow 0$, $\alpha \rightarrow 0$. Likewise, the value of a temporary sink decreases as the 'duration' of an emission reduction $(N)$ increases, ceteris paribus, because the period of sequestration ( $n$ ) becomes too small to have any value. This might well be the case for carbon stored in soil as a result of zero tillage.

Proposition 2 For fixed $n / N$, an increase in $N$ narrows the difference in importance between an emissions reduction and a carbon sequestration activity, ceteris paribus. An increase in $N$ 'lengthens' $n$ so that, with discounting, the eventual release of stored carbon (at time $n$ ) is valued much less today. If $N \rightarrow \infty$ so that an emission reduction is truly permanent, then the value of temporary storage depends only on the length of time that carbon is sequestered.

Proof The second term in the denominator of Eq. 3 approaches 0 as $N \rightarrow \infty$, so that the value of a temporary sink credit relative to a permanent one depends only on $n$ (given $\gamma$ and $r$ ). Since storage is not infinite, temporary offsets will always be less valuable than permanent emission reductions.

Proposition 3 The value of storage increases with the discount rate ( $\partial \alpha / \partial r>0)$, as illustrated in Table 3. The reason that ephemeral activities are more important relative to emissions reduction as the discount rate increases is because the inevitable release of sink $\mathrm{CO}_{2}$ at some future date is weighted much less than the early sequestration. 
Proof Differentiate Eq. 3 with respect to $r$ :

$$
\frac{\partial \alpha}{\partial r}=\frac{\left(\frac{1+\gamma}{1+r}\right)^{n} n}{(1+r)\left(1-\left(\frac{1+\gamma}{1+r}\right)^{N}\right)}-\frac{\left(1-\left(\frac{1+\gamma}{1+r}\right)^{n}\right)\left(\frac{1+\gamma}{1+r}\right)^{N} N}{\left(1-\left(\frac{1+\gamma}{1+r}\right)^{N}\right)^{2}(1+r)}
$$

The sign of $\frac{\partial \alpha}{\partial r}>0$ as long as $\frac{n}{N}>\frac{\left(\frac{1+r}{1+\gamma}\right)^{n}-1}{\left(\frac{1+r}{1+\gamma}\right)^{N}-1}$, which holds for all $n, N>0, n<N$ and $\gamma<r$. The proof is numerical. Clearly, if $n=N, \frac{\partial \alpha}{\partial r}=0$. Assume $r=0.04$ and $\gamma=0.02$. Then, if $n=1$ and $N=2$, we find $1 / 2>0.4951$; if $n=50$ and $N=100$, $1 / 2>0.2747$; if $n=250$ and $N=500,1 / 2>0.0077$; and so on.

Proposition 4 As the rate at which the shadow price of carbon $(\gamma)$ increases, the value of temporary storage relative to a 'permanent' emissions reduction decreases. However, landowners might supply more or less carbon sinks when the price of carbon is rising over time.

Proof Differentiate Eq. 3 with respect to $\gamma$ :

$$
\frac{\partial \alpha}{\partial \gamma}=-\frac{\left(\frac{1+\gamma}{1+r}\right)^{n} n}{(1+\gamma)\left(1-\left(\frac{1+\gamma}{1+r}\right)^{N}\right)}+\frac{\left(1-\left(\frac{1+\gamma}{1+r}\right)^{n}\right)\left(\frac{1+\gamma}{1+r}\right)^{N} N}{\left(1-\left(\frac{1+\gamma}{1+r}\right)^{N}\right)^{2}(1+\gamma)}
$$

The result $\partial \alpha / \partial \gamma<0$ can only be proven numerically. Assume $\partial \alpha / \partial \gamma<0$. Then, it is possible to rearrange Eq. 7 as: $\frac{n}{N}>\frac{\left(\frac{1+r}{1+\gamma}\right)^{n}-1}{\left(\frac{1+r}{1+\gamma}\right)^{N}-1}$, which holds in all cases as indicated in Proposition 3. Thus, $\partial \alpha / \partial \gamma<0$. Now denote by $S(\alpha, P, \boldsymbol{R} ; \boldsymbol{Z})$ the supply of carbon sink credits, where $\alpha$ is the relative price of 'temporary' (short duration) versus 'permanent' (long duration) credits (as before), ${ }^{4} P$ is the price of a permanent credit, $\boldsymbol{R}$ is a vector of carbon input costs, and $\mathbf{Z}$ is a vector of characteristics that describes the offset project. $\partial \mathrm{S}(\alpha, P, \boldsymbol{R} ; \boldsymbol{Z}) / \partial \alpha>0$ because supply of sink credits increases as their price increases. Then, $\frac{d S}{d \gamma}=\frac{\partial \mathrm{S}}{\partial \alpha} \frac{\partial \alpha}{\partial \gamma}+\frac{\partial \mathrm{S}}{\partial P} \frac{\partial P}{\partial \gamma}+\frac{\partial \mathrm{S}}{\partial \boldsymbol{R}} \frac{\partial \boldsymbol{R}}{\partial \gamma}$ cannot be signed because, while $\partial \mathrm{S} / \partial \alpha>0$ and $\partial \alpha / \partial \gamma<0$, so the first term is negative, the second term is positive $(\partial \mathrm{S} / \partial P>0, \partial P / \partial \gamma>0)$, and the third is unknown $(\partial \mathrm{S} / \partial \boldsymbol{R}<0, \partial \boldsymbol{R} / \partial \gamma \geq 0$ or $\partial \boldsymbol{R} / \partial \gamma<0)$.

Proposition 5 The minimum value of a carbon sink credit relative to an emission reduction credit equals the ratio of the lifetimes of the 'temporary' and 'permanent' credits, $n / N$.

Proof Only $\gamma<r$ is possible because, if $\gamma>r$, economic agents would pursue climate mitigation (by purchasing carbon sink credits) to such an extent that the rate of

${ }^{4}$ The relative price is included in the supply function to account for duration. 
growth in atmospheric $\mathrm{CO}_{2}$ (the price of carbon credits) falls enough to equalize $\gamma$ and $r$. Consider $r \rightarrow^{+} \gamma\left(\right.$ or $\gamma \rightarrow^{-} r$ ). In that case, Eq. 1 becomes $P=\sum_{t=1}^{N} q=N q$ and Eq. 2 becomes $\alpha P=\sum_{t=1}^{n} q=n q$, so that $\alpha=n / N$.

\section{Discussion}

The foregoing results have important policy implications that relate to the duration problem. It is clear that sink offset credits cannot generally be traded one-for-one for emissions reduction credits, even if the latter are not considered permanent; nor can credits from different sink projects be traded one-for-one without some adjustment for duration (say using Table 3). The conversion rate will depend on the length of time that each project keeps $\mathrm{CO}_{2}$ out of the atmosphere, and, crucially, on the discount rate. For example, if a sequestration project can ensure that carbon remains sequestered for 10 years, it is worth only 0.11 of an emission reduction that ensures no future increase in emissions for 200 years if the discount rate $(r)$ is $2 \%$ and the growth rate of damages $(\gamma)$ is $1 \%$ (Table 3 ).

When the damages from atmospheric concentrations of $\mathrm{CO}_{2}$ (shadow carbon prices) rise over time, the value of temporary sequestration will fall relative to permanent emissions reduction (Proposition 4). However, while the demand for both temporary and permanent offsets is expected to increase as the price of a permanent emissions reduction credit rises, the supply of temporary credits from biological activities might rise or fall as $\gamma$ increases-it depends on the effect that an increase in the rate of damages has on the price of permanent offsets, and the costs of inputs into biological sequestration (in any), and how these in turn relate to the effect of relative price or duration on supply.

To judge sink projects in the absence of market data requires that a policy analyst interested in cost-benefit analysis make arbitrary judgments about the discount rate, the rate of increase in damages, and the conversion rate between different biological sink projects to account for differing durations. These are over and above assumptions and uncertainty related to vegetation growth rates, uptake of carbon in soils, wildfire, disease, pests and so forth, the majority of which are not explicitly spelled out in most analyses of terrestrial sink projects.

We do not know the rate at which economic damages increase as more anthropogenic emissions of $\mathrm{CO}_{2}$ enter the atmosphere. If the rate of increase in damages equals or exceeds the discount rate, then $\mathrm{CO}_{2}$ offset credits from sink activities are only worth $n / N$ of an emissions-reduction credit (proposition 5). This is equivalent to assuming a zero discount rate for physical carbon. ${ }^{5}$ But this implies that temporary offsets from biological sink activities are overvalued because, as $N \rightarrow \infty$, the relative value of a temporary off set credit falls to zero. It is reasonable to assume that $N \rightarrow \infty$ if an emissions-reduction policy results in behavioural changes that cause permanent reductions in $\mathrm{CO}_{2}$ emissions (e.g., car manufacturers stop producing SUVs as people demand smaller vehicles).

${ }^{5}$ For a discussion of discounting physical carbon in this context see van Kooten (2004) and Boyland (2006). 
Given the difficulty of determining not only the discount rate and the growth rate in damages, but also the uncertainty surrounding $n$ and $N$, it will simply not be possible for the authority to determine a conversion factor between activities leading to carbon credits of differing duration. Perhaps one can rely on the market to determine conversion rates, but even the market will have difficulty resolving all uncertainty, and can only do so if the authority sets rules for trading off temporary and permanent credits. These are necessarily arbitrary and, given high transaction costs associated with the creation (measurement, monitoring and trading) of biological offsets, sink credits are likely to sell more cheaply than warranted. Emitters will substitute cheap sink credits for more expensive emissions reduction credits, which reduces their incentive to invest in technologies to increase efficiency. As a consequence, the 'bridging' feature of biological sink activities actually serves to reduce incentives to conduct needed research and development-it increases the length of the bridging interval required.

Finally, a country that uses carbon sequestration credits to achieve some proportion of its $\mathrm{CO}_{2}$ emissions-reduction target during Kyoto's first commitment period has avoided emissions reductions. If it is to remain committed to long-term climate mitigation, however, the country must increase its emissions-reduction target in the next commitment period. It must meet that target plus the shortfall from the previous period-it still needs to reduce the emissions that were covered by forestry activities. Further, the country is technically liable for ensuring that the stored carbon remains there, which will be difficult given the non-permanence of forest sinks. For example, a country that relies on forest sinks for one-third of a $6 \%$ reduction in emissions and commits to a further $7 \%$ reduction for the second commitment period must still reduce emissions in the second commitment period by an incredible $11 \%$. It has only reduced emissions by $4 \%$ in the first period, and must thus reduce emissions by $9 \%$ during its second period commitment. But, as the forest sink releases its carbon to the atmosphere, the country must also cover that loss, which amounts to a further $2 \%$ reduction in emissions. The temporal shifting in the emissions-reduction burden caused by reliance on carbon sinks therefore results in an onerous obligation for future generations, one which they may not be willing to accept.

\section{Addressing duration and transaction costs: a plausible approach}

We now address the two problems of greatest concern: (1) the ephemeral nature of biological sinks makes it difficult to compare biological activities with emissions reduction, while (2) keeping track of $\mathrm{CO}_{2}$ uptake and release in biological sinks requires measurement and monitoring, which are imprecise and expensive. An appropriate way to deal with the first issue-the problem of duration-is to count removals of $\mathrm{CO}_{2}$ from the atmosphere and emissions reduction on the same footing. A debit occurs whenever an anthropogenic activity releases $\mathrm{CO}_{2}$ into the atmosphere, regardless of the source. A credit is earned by removing $\mathrm{CO}_{2}$ from the atmosphere and storing it in a terrestrial sink. The credit is the mirror image of an emissions reduction-one removes $\mathrm{CO}_{2}$ from the atmosphere, the other avoids putting it there to begin with. Thus, if a forest is harvested, any carbon not stored in products but released to the atmosphere is debited (in the same way as emissions from fossil fuels). Likewise, any carbon released by decay of wood products, or any 
soil carbon released to the atmosphere, is counted as a debit at the time of release. If harvested fiber is burned in lieu of fossil fuels, a debit is also incurred but it is offset by the credit earned when growing biomass removes $\mathrm{CO}_{2}$ from the atmosphere: However, the carbon sequestered must be appropriately discounted so there is a net release in discounted $\mathrm{CO}_{2}$.

What about forest conservation or avoidance of deforestation, which accounts for more than one-quarter of all anthropogenic emissions? In some ways this is similar to the emissions situation. Credits can only be earned through emissions avoidance if there is a target level of emissions and emissions are below the target. Without a target, emissions avoidance is nothing more than avoidance of debits. True credits can only be earned by removing $\mathrm{CO}_{2}$ from the atmosphere. While it may be possible to mitigate $\mathrm{CO}_{2}$ emissions by delaying (perhaps indefinitely) deforestation, there can be no credit for doing so unless there is some target level of deforestation so that, just as in the case of emissions avoidance, one gets credits by being below the target. Otherwise, the only benefit results from the avoidance of debits.

With this accounting framework, a country's debits minus credits, or net debits, constitute its annual emissions. The country can choose to tax debits and subsidize credits (e.g., see van Kooten et al. 1995), or cap net debits and then permit trade. The only real obstacle that remains to be overcome relates to the measurement and monitoring of carbon uptake and release from a terrestrial sink, which greatly increase transaction costs.

A straightforward way of reducing transaction costs in this case is to employ contracts between the authority (government, trading exchange) and a landowner. The contract specifies the change in land use that the landowner will implement and an accompanying schedule of carbon flux-annual $\mathrm{CO}_{2}$ uptake for each year the land use change is in place and release when the land use changes, either to the previous use or some other. It also specifies the length of time that the land is to be kept in its new use and the penalties if the contracted-for use changes (including denudation due to wildfire, etc.), including requirements that the landowner purchase certain emissions reduction offsets or pay penalties. Transaction costs are minimized because only the change is land use needs to be monitored and not the $\mathrm{CO}_{2}$ flux or anything else, although there is the cost of writing a contract. Under these circumstances, contracts can be traded in carbon markets, although it is likely that few would undertake to do so based on Tables 1 and 2. Alternatively, through international negotiations, countries could set different targets for emissions reduction and biological sink activities, again using contracts with landowners to minimize transaction costs and facilitating exchange of contracts in a separate market.

\section{Conclusions}

Our main conclusion is that terrestrial ecosystem activities to generate $\mathrm{CO}_{2}$ offset credits are a distraction from the actual job of mitigating climate change. While there is no question that carbon can be stored in biological sinks, and that care should be taken to foster such sinks and ensure that carbon is not unwontedly and needlessly released (e.g., via deforestation), the primary focus of climate change mitigation should be on policies that reduce greenhouse gas emissions. There are several reasons for this. Measurement, monitoring and verification of sink activities 
is particularly difficult, resulting in high transaction costs that need to be added to the price at which temporary credits will trade. Transaction costs are sufficiently large that most sink projects would no longer be economically viable to pursue based on estimates in Tables 1 and 2. This is even more so the case if stored carbon must be accounted for in perpetuity. Second, while it makes some sense to encourage carbon sinks because they offer a bridge to enable development of technologies with lower fuel emissions (e.g., more efficient vehicles), permitting below-cost sales of sink credits in carbon markets will result in reduced incentives to invest in new technologies.

Rent seeking by opportunistic sellers of carbon credits, and even by environmental groups, highlights another important problem: terrestrial sinks remove $\mathrm{CO}_{2}$ from the atmosphere at different rates and store it for varying lengths of time, with both removal rates and storage times embodying significant uncertainty. This facilitates the marketing of dubious sink offset credits. While this duration problem can readily be solved (e.g., taxing emissions and subsidizing removals at the time they occur), given the high transaction costs of including sink activities and the reluctance of countries to make sinks work, the only conclusion is that great care must be taken, and appropriate institutions put in place, before terrestrial ecosystem sink activities can be included in a carbon trading system.

Acknowledgements Earlier versions of this paper were presented in Vancouver, Canada, at the Canadian Economics Association annual meetings in June 2008; in Ghent, Belgium, at the European Association of Agricultural Economists in August 2008; and in Den Haag, The Netherlands, at the Landbouw Economisch Instituit of Wageningen University in September, 2008. Comments provided by participants at these meetings, and especially Leslie Shiell, are greatly appreciated. The author also wishes to acknowledge helpful comments and suggestions from an anonymous journal reviewer.

Open Access This article is distributed under the terms of the Creative Commons Attribution Noncommercial License which permits any noncommercial use, distribution, and reproduction in any medium, provided the original author(s) and source are credited.

\section{References}

Baker JM, Ochsner TE, Venterea RT, Griffis TJ (2007) Tillage and soil carbon sequestration: what do we really know? Commentary. Agric Ecosyst Environ 118(1-4):1-5

Boyland M (2006) The economics of using forests to increase carbon storage. Can J of Forestry Research 36:2223-2234

Dutschke M (2002) Fractions of permanence-squaring the cycle of sink carbon accounting. Mitig Adapt Strategies Glob Chang 7(4):381-402

FAO (2004) A review of carbon sequestration projects. Land and Plant Nutrition Service, Land and Water Development Division, Food and Agriculture Organization of the United Nations, Rome, Miscellaneous paper AGL/MISC/37/2004

Government of Canada (2002) Climate change plan for Canada. Government of Canada, Ottawa

Herzog H, Caldeira K, Reilly J (2003) An issue of permanence: assessing the effectiveness of temporary carbon storage. Clim Change 59(3):293-310

IPCC (Intergovernmental Panel on Climate Change) (2000) Land use, land-use change, and forestry. Cambridge University Press, New York

Lal R (2004a) Offsetting China's $\mathrm{CO}_{2}$ emissions by soil carbon sequestration. Clim Change 65: $263-275$

Lal R (2004b) Soil carbon sequestration in India. Clim Change 65:277-296

Manley J, van Kooten GC, Moeltner K, Johnson DW (2005) Creating carbon offsets in agriculture through zero tillage: a meta-analysis of costs and carbon benefits. Clim Change 68:41-65 
Marland G, Fruit K, Sedjo R (2001) Accounting for sequestered carbon: the question of permanence. Environ Sci Policy 4(6):259-268

Olson KR, Lang JM, Ebelhar SA (2005) Soil organic carbon changes after 12 years of no-tillage and tillage of Grantsburg soils in southern Illinois. Soil Tillage Res 81(2):217-225

Parson EA, Keith DW (1998) Fossil fuels without $\mathrm{CO}_{2}$ emissions. Science 282(5391):1053-1054

Riddel M, Shaw WD (2003) Option wealth and bequest values: the value of protecting future generations from the health risks of nuclear waste storage. Land Econ 79(4):537-548

Sathaye JA, Makundi WR, Andrasko K et al (2001) Carbon mitigation potential and costs of forestry options in Brazil, China, Indonesia, Mexico, the Philippines and Tanzania. Mitig Adapt Strategies Glob Chang 6:185-211

Sedjo RA, Marland G (2003) Inter-trading permanent emissions credits and rented temporary carbon emissions offsets: some issues and alternatives. Climate Policy 3(4):435-444

Slangen LHG, Loucks LA, Slangen AHL (2008) Institutional economics and economic organisation theory: an integrated approach. Wageningen, Netherlands

Stockfisch N, Forstreuter T, Ehlers W (1999) Ploughing effects on soil organic matter after 20 years of conservation tillage in Lower Saxony, Germany. Soil Tillage Res 52(1):91-101

Subak S (2003) Replacing carbon lost from forests: an assessment of insurance, reserves, and expiring credits. Climate Policy 3:107-122

The Economist (2007) Coal power. Still going strong The Economist 17 Nov pp 71-72

van Kooten GC (2004) Climate change economics. Edward Elgar, Cheltenham, UK

van Kooten GC, Sohngen B (2007) Economics of forest carbon sinks: a review. Int Rev Environ Res Econ 1(3):237-269

van Kooten GC, Binkley CS, Delcourt G (1995) Effect of carbon taxes and subsidies on optimal forest rotation age and supply of carbon services. Am J Agric Econ 77:365-774

West TO, Marland G (2002) A syntheis of carbon sequestration, carbon emissions, and net carbon flux in agriculture: comparing tillage practices in the United States. Agric, Ecosystems \& Environ 91(September):217-232 